\title{
DOCUMENTOS HISTÓRICOS E ARQUEOLÓGICOS COMO LOCUS DE INVESTIGAÇÃO, PODER E REPRESENTAÇÃO
}

\section{HISTORICAL AND ARCHEOLOGICAL DOCUMENTATION AS A LOCUS OF INVESTIGATION, POWER AND REPRESENTATION}

\author{
Gabriela Gonçalves Junqueira ${ }^{1}$
}

Toda definição acabada é uma espécie de morte, porque, sendo fechada, mata justo a inquietação e curiosidade que nos impulsionam para as coisas que, vivas, palpitam e pulsam (SANTAELLA, 1983, p. 9 apud GHENO; MACHADO, 2013).

\begin{abstract}
Resumo
O presente trabalho pretende discutir e suscitar reflexões acerca da presença do poder e da política de interesses que rondam documentos históricos e arqueológicos. Para tal, será utilizado breve relato de documentação histórica e narrativas derivadas de suas leituras a fim de identificar como o poder se manifesta na escrita, a partir da História. Além disso, irei lançar luzes no cenário de institucionalização da Arqueologia para entender suas influências e como ainda hoje, um espectro descritivo e tecnicista usado como aparato teórico-metodológico atua em prol de identificar e imobilizar povos produtores de suas materialidades. Sendo assim, as reflexões apontam para uma compreensão antropológica e reflexiva acerca desses povos, em específico os Jê meridionais, para que seja possível superar esses discursos e narrativas marcadas pelo poder.
\end{abstract}

Palavras chave: Jê meridionais. História Indígena. Etnoarqueologia. Colonialidade do poder.

\begin{abstract}
The present work aims to discuss and raise reflections on power and the politics surrounding historic and archaeological documents. To that end, it is applied a brief account based on the readings of the historic documentation and narratives in order to identify how power manifest itself through writing, from the standpoint of History. Beyond that, I will shed lights in the institutionalization scenario of Archeology to understand their influences and, as still continues as a descriptive and technician spectrum used as a theoretical - methodological apparatus acting in favor of the identification and immobilization of the people as they produce their own materiality. Therefore, the reflections points to a reflexive anthropological
\end{abstract}

\footnotetext{
${ }^{1}$ Doutoranda em Antropologia Social pela Universidade Federal de Goiás (UFG). Professora da Rede Estadual de Ensino de Minas Gerais e professora substituta do Instituto de Ciências Sociais (INCIS) da Universidade Federal de Uberlândia (UFU). Pesquisadora no Grupo de Estudos e Pesquisas em Arqueologia, Etnologia e História Indígena (GEPAEHI), da Universidade Federal de Uberlândia (UFU). Graduada em Ciências Sociais e Mestre em Ciências Sociais pela Universidade Federal de Uberlândia (UFU).
} 
comprehension of those people, the Jê Meridionais in particular, so as to be possible to overcome those power shaped discourses and narratives.

Keywords: Southern Jê. Indigenous History. Etnoarchaeology. Coloniality of power.

\section{DOCUMENTOS HISTÓRICOS E ARQUEOLÓGICOS COMO LOCUS DE INVESTIGAÇÃO, PODER E REPRESENTAÇÃO}

O presente trabalho pretende discutir e suscitar reflexões acerca da presença do poder e da política de interesses que rondam tanto documentos históricos, quanto documentos arqueológicos. Para tal, será utilizado breve relato de documentação histórica e narrativas derivadas de suas leituras a fim de identificar como o poder se manifesta na escrita, a partir então da História. Além disso, irei lançar luzes no cenário de institucionalização da Arqueologia para entender suas influências e como ainda hoje, um espectro descritivo e tecnicista usado como aparato teórico-metodológico atua em prol de identificar e imobilizar povos produtores de suas materialidades.

A intenção é partir de documentações históricas já discutidas em trabalhos anteriores quanto aos povos Jê meridionais que nos séculos XVIII e XIX ocuparam a área que compreende hoje o sul de Goiás, Triângulo Mineiro e norte de São Paulo. Essa área foi palco de um intenso convívio e diferentes estratégias de contato com as alteridades e teria sido um território de ocupação histórica desse grupo que sempre foi descrito nas narrativas das documentações oficiais como gentios bárbaros e selvagens.

Vale ressaltar que esse grupo era descrito como "gentio Caiapó”, contudo, sabe-se hoje que a nomenclatura Kayapó ${ }^{2}$, pouco nos diz acerca do etnônimo, o termo na verdade é de origem Tupi, e pode ser traduzido "como macaco" (TURNER, 1992). Por essa razão acredito ser mais apropriada a utilização da denominação Jê meridionais, já que este grupo pertencia à família linguística Jê, derivada do tronco Macro-Jê, e suas características, bem como falar língua diversa da geral - Tupi -, habitar provavelmente em sua maioria aldeias circulares, e praticar vários rituais advindos destes grupos, derivam daí.

Ademais, o termo "Caiapó" pode englobar outros grupos, que não necessariamente poderiam ser Kayapó, mas que ao olhar do não-indígena, estes grupos deveriam compartilhar algumas características comuns para serem retratados pelo mesmo termo, sendo assim, seria um termo genérico.

\footnotetext{
2 Vale destacar a diferença dos termos "Cayapó" e "Kayapó", no qual o primeiro termo era o utilizado nos documentos oficiais, cartas e relatos aqui utilizados como fontes, e o segundo, termo utilizado e adotado atualmente pela Associação Brasileira de Antropologia.
} 
Além disso, essa exononímia a qual me refiro, reproduzida pelos colonizadores, pode ter sido resultado de um discurso claramente marcado pela colonialidade do poder (QUIJANO, 2005). Esse grupo, marcado pela ação guerreira em contato com o outro, foi sempre descrito nas documentações e relatos como selvagens, bárbaros e amantes da carne humana. Narrativas, que marcadas pelo poder e por interesses unilaterais tendia a tornar estáticos grupos fluídos dentro de determinadas hierarquias, além de tornar genéricos (QUIJANO, 1999) grupos que tinham diferenças e especificidades nas suas vidas e organizações sociais.

Essa narrativa exime os grupos de suas pluralidades e dinâmicas, tendendo também a anular e incentivar um "apagamento" de suas subjetividades. Age por meio da manipulação de visões para que não haja identificações com certos grupos, o que faz com que nós, partes desse processo forçado e violento de colonização, tenhamos imagens distorcidas de nós mesmos.

A indicação de uma reflexão decolonial para se pensar esses povos se dá por se tratar de uma alternativa epistêmica para se superar essa colonialidade do poder que se estende ao saber, ao ser e ao fazer (QUIJANO, 1999). Dessa forma se tem uma possibilidade de suplantar essas estruturas de dominação, exploração e conflitos que se instaurou no processo violento e opressor de colonização.

O desmantelamento dos mitos criados pelo eurocentrismo como perspectiva hegemônica do conhecimento, bem como seus principais mitos fundacionais (QUIJANO, 2005) giram em torno dos ideais do evolucionismo e do dualismo. Além da noção criada quanto ao conceito de raça, que passou a ser utilizado de meras características fenotípicas para servir à um projeto eurocêntrico de colonização, manipulação e controle que utilizou do conceito para hierarquizar e deixar estáticas populações dentro de determinados dualismos que levaram e levam ainda hoje grupos inteiros a uma infinidade de violências físicas, simbólicas e epistêmicas.

Dito isso, podemos afirmar que o potencial guerreiro destes indígenas foi, portanto, utilizado de maneira a chancelar as mais diversas atrocidades contra essa população. Os colonizadores ressaltavam a violência com que estes indígenas se lançavam contra os brancos para justificar a necessidade de se fazer guerra contra eles, pois o ataque às aldeias só era legítimo em casos de Guerra Justa, ou seja, guerra contra índios que se configurariam como índios hostis e, portanto, inimigos passíveis de serem escravizados (MARTINI, 2008).

A Guerra Justa ainda poderia ser legítima quando o inimigo recusasse a conversão ou impedisse a propagação de seus preceitos religiosos, praticassem hostilidades contra os portugueses ou aliados da Coroa ou, então, ainda se rompesse algum pacto estabelecido, lembrando que aos 
índios que sobrevivessem às guerras justas, ficariam permitidos os manterem sob regime de escravidão legal (PERRONE-MOISÉS, 1992).

[...] mandando fazes guerra offensiva a estes barbaros, pois he o unico e cabal remedio que the achamos, por menos foi castigado e destruido o gentio Payagoâ, no caminho do Cuyaba. ${ }^{3}$

O que não se pode aceitar sem uma reflexão crítica é a utilização da marca guerreira desses povos de maneira superficial, como uma busca sangrenta e violenta pela morte do adversário. A guerra para eles não estaria associada a atos bárbaros e selvagens, como se fez crer nos discursos oficiais, e nem à espacialidade de seu tratamento teórico como função (FERNANDES, 1970), ou à sua natureza universal (CLASTRES, 2004) ou reciprocidade (LÉVI-STRAUSS, 1976) como uma tendência que reduz a guerra a uma modalidade particular de troca ${ }^{4}$.

A guerra estaria relacionada, então, a formação da pessoa, identidades e corpos. Enquanto consumo produtivo, pode ser vista como predação do mundo exterior para a produção do mundo interior entre esses povos. A guerra seria assim, considerada parte de um consumo produtivo, seja pela necessidade de uma redução ao discurso da reciprocidade, seja pela integração da guerra ao tema da produção ontológica, que é um fenômeno da esfera produtiva, e não do consumo propriamente dito, no qual a motivação e a ação de guerra é a de predar o exterior para produzir o interior (aquisição de almas, virtualidade de pessoas, nominação, existência etc.) (FAUSTO, 2001).

Com essa noção deturpada e funcional da guerra para servir aos interesses das frentes de expansão colonial afim de justificar o extermínio desses povos, verdadeiros entraves a invasão e exploração colonizadora, podemos ver a forma cruel com que o poder se manifesta. Fato que resulta em um dos contatos mais violentos e cruéis entre indígenas e não-indígenas em toda América colonial portuguesa.

Visualizar essas possibilidades de entendimento do material histórico, como vislumbrar outras possibilidades da ação guerreira, só foi possível por meio do olhar proposto pela Antropologia. É a perspectiva da alteridade que permite um novo olhar e novas interpretações a documentação histórica e com isso um esclarecimento e a tentativa de preencher lacunas na história indígena quanto ao passado desses povos.

\footnotetext{
${ }^{3}$ CARTA dos oficiais da Câmara de Vila Boa, ao rei [D. José], expondo as atrocidades cometidas pelos índios Caiapós e insistindo na guerra ofensiva como único meio de repressão. 1757, junho, 11. AHU_ACL_CU_008, Cx.14, D.856.

4 A menção a esses autores e visões se faz pela importância dessas discussões para as teorias gerais sobre a guerra e não necessariamente a guerras associadas somente aos povos Jê. Para um aprofundamento nessa relação sugiro a leitura da minha dissertação.
} 
Além da perspectiva da alteridade direcionada ao material histórico, é necessário que a eles sejam feitas também uma leitura "a contrapelo" (BENJAMIN, 1985). A proposta é se "escovar a história a contrapelo", chamando a atenção para que a história seja lida e analisada por meio do ponto de vista dos "vencidos", o que nos afasta de uma história oficial, e que não permite uma identificação com os colonizadores, que foram por um longo período vistos como os heróis civilizadores da América. Nesse sentido, a orientação para se ler a história “a contrapelo” caminha em conjunto com a proposta de uma nova história indígena (MONTEIRO, 2001) que se configura de forma cada vez mais efetiva e necessária.

Abordagens histórico-antropológicas permitem novas compreensões sobre o lugar dos índios em nossa história e segundo Almeida (2013) e Monteiro (2001) defensores das causas indígenas, há a urgência dessa revisão historiográfica para que haja um enterro definitivo de uma historiografia que por muitos anos foi parceira de políticas de apagamento de identidades indígenas.

Essa revisão historiográfica indicada por esses autores era tão necessária quanto peremptória, haja vista, por exemplo, como alguns autores como Martius (1907) retrataram os indígenas dentro da História do Brasil. O alemão foi ganhador do concurso do Instituto Histórico Geográfico Brasileiro, o IHGB, sobre o melhor manual sobre como deveria ser escrita a história do Brasil. O autor de obras de impacto para os historiadores do século XIX, ficou reconhecido por incorporar o negro e o índio na formação da história e da identidade nacional. O fato, é que o autor defendia a tese da degeneração indígena em seus relatos, ora por um determinismo ambiental, ora pela mistura e ainda pela suposta homossexualidade, que segundo o autor seria a ruína desses povos de úteros infecundos (NOELLI; FERREIRA, 2007).

Tal raciocínio nos permite uma ponte da História para Arqueologia. Tais disciplinas dialogaram de forma muito próximas, talvez mais entre si, do que qualquer uma delas com a Antropologia. O que talvez marque ainda mais a existência de um poder, ora descarado, ora latente.

A Antropologia desde seu surgimento tem uma relação direta com o colonialismo. Ela surge a fim de justificar a colonização de povos menos civilizados, pensamento esse que inaugura a primeira corrente teórica antropológica, o evolucionismo. Contudo, hoje a Antropologia é marcada pela compreensão e entendimento da diferença, pela relação entre diferentes alteridades, e sem essa reflexividade proposta hoje pela Antropologia, seria difícil sair dessa armadilha arbitrária que muitas vezes a História e a Arqueologia propôs, mas que com alguns debates tentam propor reflexões nesse sentido (NOELLI; FERREIRA, 2007).

Esses determinismos que vimos no passado da historiografia sobre a história do Brasil é uma característica que também cerca a Arqueologia. Ainda hoje a Arqueologia conta com 
instrumentos de análises que são resultados de influências de conceitos muito criticados do século XIX, como o determinismo ambiental, presente nas obras de Martius, e explorada em reflexões sobre o tema pelos historiadores Noelli e Ferreira (2007).

Ao revisitar a história do desenvolvimento da Arqueologia brasileira, a teoria da degeneração indígena e a permanência de representações arqueológicas colonialistas são duas características muito claras na visão dos autores com quem diálogo.

A Arqueologia e seu desenvolvimento como disciplina acadêmica contou com a presença e influência de especialistas estrangeiros, principalmente quanto as técnicas e métodos de escavação, classificação, datação e documentação dos acervos arqueológicos.

Esses especialistas claramente vinham imbuídos de suas correntes teóricas, e a influência francesa, por exemplo, trouxe para as universidades a noção de uma Arqueologia como estudo do passado pré-histórico humano (BARRETO, 1999/2000). Algo que para nós, antropólogas e antropólogos, é ambíguo e imbuído de perigos, pois pode afirmar que os povos que viveram em um período sem escrita, são um povo sem história.

Uma forma de poder que se manifesta não só nessa influência francesa a Arqueologia, mas que influenciou historiadores e até mesmo antropólogos a adquirirem essas afirmações, legitimando assim, somente a documentação escrita, como prova de um passado existente e dotado assim de uma história chancelada. Vale destacar que hoje, como uma forma de superar essa visão, muitos arqueólogos brasileiros já utilizam da expressão "pré-colonial" no lugar de "pré-histórico" (BARRETO, 1999/2000).

A Arqueologia, institucionalizada então no Brasil no Instituto Histórico e Geográfico Brasileiro e no Museu Nacional nasce em prol não só de avanços científicos, mas também de interesses e representações políticas. E como a Antropologia, coube a Arqueologia não só o estudo do "indígena morto", mas também do indígena vivo, "escrutá-lo em seus graus de civilização para estipular uma política colonial, para selecioná-lo e arregimentá-lo como mão-de-obra sucedânea aos braços escravos. Quanto mais civilizado, melhor operário seria um indígena” (Ferreira, 2003, 2005 apud NOELLI; FERREIRA, 2007).

Além dessas questões e da intervenção francesa, a influência americana, a qual tem seus principais nomes em Betty Meggers e Clifford Evans marcou e marca ainda hoje essa ciência. A vinda do casal no final dos anos 1940 foi financiada pelos Estados Unidos, e em 1965 eles criam o 
Programa Nacional de Pesquisas Arqueológicas, o Pronapa, programa que inclusive foi apontado por alguns artigos com uma possível ligação e parcerias com a ditadura militar ${ }^{5}$.

As pesquisas de Meggers na Amazônia propôs que as condições ambientais da várzea amazônica impediram o desenvolvimento local de sociedades complexas (BARRETO, 1999/2000), sendo um ambiente que não possibilitava assim o desenvolvimento das sociedades indígenas, que como já vimos, tinha seu desenvolvimento visto pela via da degeneração e marcada pelo determinismo ambiental que rondava os pensamento e teorias da autora. Cenário que hoje serve como ponto de partida e contestação por meio de novas descobertas e perspectivas de arqueólogos brasileiros (Neves 1998), como afirma Funari (2013) em reflexões sobre o surgimento e desenvolvimento da Arqueologia no Brasil.

Meggers morreu há pouco tempo e defendeu até a morte não apenas que a América Latina seria para sempre atrasada e subdesenvolvida, mas também que a floresta tropical era um paraíso falso, iludindo trabalhadores árduos a se tornarem índios preguiçosos. (FUNARI, 2013, p. 25)

O programa treinou uma geração de arqueólogos brasileiros, e até os dias de hoje, é uma referência. Ele segue influências da Ecologia Cultural e do neo-evolucionismo, que prioriza os fenômenos naturais ao construir interpretações sobre mudança social e por isso, materiais coletados são classificados segundo as categorias de fase e tradição (GASPAR, 2003). Um discurso marcado pelo poder e por interesses políticos.

Os princípios teóricos e empíricos eram muito reacionários e anti-humanistas, promovendo o conceito de que os povos nativos eram preguiçosos e o país pobre devido às condições naturais. (FUNARI, 2013, p. 24)

Cabe salientar que entende-se por tradição, sítios e conjuntos de materiais arqueológicos considerados diagnósticos que se repetem, com frequência, ao longo de um período e se distribuem em um amplo território, um artifício metodológico para identificar, classificar e compreender o vasto universo de vestígios materiais de diferentes grupos sociais (ETCHEVARNE, 2012).

Cada tradição é composta por um grupo denominados de guia fóssil de identificação. $O$ guia fóssil pode ser entendido então, como os materiais que permitem a identificação e relação do vestígio arqueológico a determinada tradição. Como exemplo, na Tradição Tupiguarani, o guia

\footnotetext{
${ }^{5}$ Para saber mais sobre essa relação sugiro a leitura de Funari, Pedro Paulo A. Archaeology in Brazil: politics and scholarship at a crossroads. World Archaeological Bulletin, Southampton, v.5, p.123-132, 1991.
} 
fóssil está ligado ás cerâmicas corrugadas, pintadas e decoradas, enquanto que na Tradição AratuSapucaí, o guia fóssil são os potes germinados e as cerâmicas escuras e lisas, que muitas vezes são retratadas como cerâmicas "simples", uma narrativa que já difere certo grau de complexidade e grau evolutivo entre as práticas cerâmicas.

Diante isso, podemos levantar reflexões no sentido de que as Tradições pensadas em conjunto aos guias fosseis são classificações e modelos construídos por uma arqueologia tradicional ainda influenciada pelas propostas pronapianas de trabalho. Uma visão que aponta linearidades e continuidades onde existe processos e múltiplas interpretações possíveis. Em um novo movimento, de aproximação da Antropologia, essas Tradições se mostram insuficientes, pois enquadram uma materialidade resultante de movimentos e dinâmicas em classificações fixas e estáticas.

Enquanto instrumentos para se pensar o contexto cultural provavelmente vividos nos sítios arqueológicos, essa noção de tradição fixa retira o movimento, a dinâmica e a agência dos produtores dessa materialidade e da própria materialidade produzida enquanto relação entre agentes.

Além dessas críticas ao instrumento de estudo e análise de vestígios arqueológicos, as Tradições, ressalto ainda que os pesquisadores coordenadores do projeto trouxeram influências do neoevolucionismo da arqueologia americana. Contudo, vale destacar que essa orientação teve menor impacto aos estudos arqueológicos, pois categorias evolutivas ou escalas evolutivas, nunca foram utilizadas de maneira devassada ou escancarada nas classificações.

Como já foi dito, o Pronapa escolheu organizar seus dados nas categorias também americanas de "fases" e "tradições", que apesar de muito questionadas por arqueólogos, ainda organizam suas pesquisas e classificações com tais metodologias (BARRETO, 1999/2000).

Porém, alguns autores segundo Pedro Paulo Funari (2013) como Anna Roosevelt refletiu e desafiou essas classificações e padronizações propostas por Meggers no cenário amazônico. A autora inovou propor para o ambiente um enorme potencial de abrigador de ocupações, além de levantar novas questões como as discussões de gênero e o papel da mulher no passado pré-colonial do Brasil.

Contudo, o conceito de fase e tradição, central para o Pronapa, se transformou na finalidade última das pesquisas para um número significativo de arqueólogos entre as décadas de 1960 e 1980 (DIAS, 2007) ao invés de ser um caminho para atingir determinados entendimentos e compreensões acerca da realidade material. Vale ressaltar que o conceito de tradição sugere uma unidade ou uma série de unidades arqueológicas básicas (fases) relacionadas entre si, que são socialmente transmissíveis e persistentes no tempo. Assim, uma tradição seria caracterizada 
principalmente pela profundidade temporal (DIAS, 2007, p. 62), o que traz a noção de continuidade e corrobora para um política de poder e imobilização da materialidade, o que tira toda a agencia dessa materialidade, sua história de vida, bem como das pessoas que a produziram.

Noções que talvez o distanciamento da Antropologia trouxe para a Arqueologia e que corroborou com esse processo de estabilizar e tornar fixo entendimentos acerca da materialidade. O olhar antropológico e a aproximação da Arqueologia da Antropologia é fundamental nesse sentido, pois permite enxergar uma espécie de "alma nas coisas", sempre em conjunto com os atores sociais, sendo esse olhar responsável pelo não congelamento do objeto e o não isolamento da cultura na agência (SILVEIRA; LIMA FILHO, 2005), o que possibilita possíveis e múltiplas interpretações.

Vê-se que as limitações dessas classificações e padronizações causadas pelo aparato teóricometodológico pautados nos ideais do Pronapa não foram levadas a sério e a falta de reflexão teórica na Arqueologia brasileira da década de 1960 propiciou uma visão míope quanto a abrangência do método (DIAS, 2007), que ficou preso ao nível descritivo e técnico de análise. Ressalto que hoje temos trabalhos no âmbito da Arqueologia que propicia discussões e reflexões nesse sentido mais acurado, como o trabalho de Fabíola (SILVA, 2002) que propõe diferentes possibilidades de interpretação do material arqueológico por meio de um diálogo interdisciplinar incorporando outras perspectivas, como a mitologia, por exemplo, na leitura dessa materialidade.

Além disso, ao se referir a sítios históricos, ou seja, sítios de contato, o uso desse aparato teórico-metodológico clássico, sustentado pelas classificações de fases e tradições, se mostra ainda mais frágil. A visão reducionista que o Pronapa propõe com o uso de tradições e fases para análise de material, (GASPAR, 2003) marcado muitas vezes pelo determinismo ambiental, pouco se adequa à interpretação de fenômenos em sítios de contato. A Arqueologia percebe essa inadequação, mas insiste na falha técnica. O Pronapa cria uma nova tradição, a Neobrasileira, que em tese seria instrumento de análise de sítios históricos. Contudo, o nível analítico e descritivo da nova tradição não é suficiente para interpretar e refletir sobre a complexidade material que salta aos olhos dos arqueólogos com as múltiplas possibilidades de contato.

Nesse sentido, a História também começa a rever criticamente o potencial informativo do documento escrito. Assim como a Arqueologia começa a valorizar outras evidências de materiais, que também são consideradas documentos. São vistos como documentos na medida em que que essa materialidade permite lançar "um novo olhar" sobre determinadas realidades sociais e permitem assim a possibilidade de amplificar vozes de segmentos menos privilegiados que não tiveram a oportunidade de registrar, por escrito, a sua experiência social (GASPAR, 2003). 
Pensando no desenvolvimento dessa Arqueologia no Brasil, surge uma Nova Arqueologia como Maria Dulce (2003) afirmou, ou Arqueologia Processual, que teve adeptos, mas recebeu infindáveis críticas por sua influência neo-evolucionista. Somente com o que chamamos de Arqueologia Pós-processual é que se abre um leque interpretativo da materialidade, possibilitando assim uma visão mais completa e abrangente dos contextos arqueológicos. O que caminha em conjunto com a noção de "coisa" trabalhada por Ingold (2012), quanto a sua diferença de um objeto, já que estamos falando de materialidades, no qual se foca na agência e fluidos vitais presentes nessa materialidade antes vista enquanto objeto, enquanto obra acabada.

O objeto coloca-se diante de nós como um fato consumado, oferecendo para nossa inspeção suas superfícies externas e congeladas. Ele é definido por sua própria contrastividade com relação à situação na qual ele se encontra (Heidegger 1971, p. 167). A coisa, por sua vez, é um “acontecer", ou melhor, um lugar onde vários aconteceres se entrelaçam. Observar uma coisa não é ser trancado do lado de fora, mas ser convidado para a reunião. (INGOLD, 2012, p. 29)

Com o pós-processualismo, a Arqueologia propicia a apropriação de aparatos teórico metodológicos tanto da Antropologia, quanto da História. Ao estabelecer, por exemplo, analogias com grupos contemporâneos, há uma valorização do que chamamos de projeção etnográfica, ou seja, por meio do estudo e análise de etnografias contemporâneas há o intuito de iluminar reflexões e fomentar hipóteses sobre as populações do passado. Vale destacar que o uso possível e legítimo da prática da projeção etnográfica, vem da existência de algumas características comuns aos povos Jê, como, por exemplo, o dualismo que parece regular a vida social e simbólica desses povos.

Nesse sentido, a intenção de enxergar a Arqueologia como sujeito da Etnografia, uma Arqueologia Etnográfica (CASTAÑEDA, 2008), sugere seus métodos incorporados a uma prática arqueológica para estudar o passado. Essa indicação caminha em conjunto com a projeção etnográfica, aparato metodológico da Antropologia, e pode ser visto na valorização dos estudos da etnoarqueologia.

Além disso, acredito que o uso do paradigma indiciário, metodologia histórica, e minha opção de leitura dos documentos históricos, seja também apropriada aos documentos arqueológicos. A Arqueologia que busca explicar as mudanças e aspectos sociais e culturais das sociedades humanas para compreender as dinâmicas de sociedades que já não existem atua muitas vezes como a História, e por isso considero utilizar o mesmo instrumento de análise e leitura desse documentos, assim como fazemos com os documentos oficiais, cartas e relatos. Por meio do registro arqueológico, incluindo sítios, artefatos, restos de alimentação, e outros, é necessário que 
se trabalhe como um detetive, agindo assim pelos indícios e vestígios como nos alerta o método do paradigma indiciário de Ginzburg (1989).

Tudo isso, tem relação com a proposta de uma Arqueologia Histórica, e que hoje guia estudos e pesquisas de vários arqueólogos e historiadores brasileiros, como Funari (1996) e Gheno; Machado (2013). Assim como no pós-processualismo, há aqui um encorajamento de vozes antes silenciadas na Arqueologia. Longe do viés interpretativo possibilitado e defendido por uma Arqueologia Pós-processual não havia a busca de múltiplas perspectivas dessas "coisas" (INGOLD, 2012), o que afastava também o caráter reflexivo que a Arqueologia hoje pode ter.

Se a Arqueologia Processual havia proclamado a explicação dos fenômenos culturais do passado, a Arqueologia Pós-processual conclama a interpretação desse passado. Essa nova linha teórica é marcada por uma enorme diversidade de abordagens, por vezes até mesmo opostas, assim, o "pós" que caracteriza essas Arqueologias está associado tanto ao fato dessas posturas se colocarem como críticas ao paradigma processual, que as antecedeu, como a sua aproximação às filosofias pós-modernas e à crítica pós-colonial. Contudo, temos como ponto comum a crítica quanto ao fato da Arqueologia Processual considerar a cultura material como reflexo passivo do comportamento humano, enquanto que para os pós-processualistas, a cultura material também é ativa, sendo mediada por crenças, práticas e significados. (WICHERS, 2015, p. 14)

Com esse diálogo propiciado pela Arqueologia Pós-processual e por uma Arqueologia Histórica, há uma valorização de interdisciplinaridades e das múltiplas fontes, o que permite também a aproximação da disciplina com a História e a Antropologia, não negligenciando que a Arqueologia Processual também tem reflexões no âmbito da interdisciplinaridade.

Cabe pensar o que este domínio da Arqueologia tem de particular. O aspecto ímpar da Arqueologia Histórica é a sua capacidade de dispor simultaneamente do registro documental e do registro arqueológico, ou seja, daquilo que foi escrito e o que realmente foi feito. E, da confrontação dos dois, construir interpretações que evidenciem novas leituras da realidade que se propõe a investigar. (GASPAR, 20013, p. 278/79)

A citação de Gaspar, permite uma reflexão. Se antes, por muito tempo, acreditava-se que aquilo que foi escrito era de fato o que foi vivido, hoje isso já se desmoronou. O conjunto de diversas fontes, frente a confrontação, que a meu ver, é permitido pelo olhar antropológico a essas fontes, revela as várias facetas do poder que possibilitou as inúmeras formas de violência e discriminação com populações indígenas. Um exemplo empírico disso, desse confronto entre material escrito e material arqueológico filtrado pela Antropologia fica claro quanto a discussões de minhas pesquisas. 
Como pudemos ver em citações no começo desse trabalho, os Jê meridionais, nos séculos XVIII e XIX eram populações que, pela "verdade” da documentação oficial, eram marcados pelas característica guerreira. Povos bárbaros e selvagens, comedores de carne humana, não tinham outro modo de se relacionar com o outro, não fosse pela guerra. Hoje é possível levantar outras hipóteses, por meio de descobertas materiais ${ }^{6}$. Esses levantamentos, assentido pelo olhar acurado que a Antropologia permite, em comparação com uma Arqueologia Tradicional, revelou possibilidades de diferentes maneiras e estratégias de contato com as distintas alteridades, evidenciando a agencia desses indígenas e também o potencial interpretativo da materialidade, pois a "cultura material" pode não só complementar as informações textuais, como fornecer informações de outra forma não disponíveis e até mesmo se contrastar às fontes escritas (FUNARI, 2002) ou outras fontes.

\section{Conclusão}

Essa reflexão permeou a identificação e as inúmeras possibilidades que o poder, latente ou não, traz na documentação escrita e também na documentação arqueológica. Além disso, esse poder, que permite determinadas continuidades entre diferentes categorias e disciplinas, tem sido responsável pela forma com que as sociedades indígenas vinham sendo enxergadas por uma história indígena ainda presa à colonialidade do poder tão central nesse texto. Uma história indígena que acreditava na "pureza" dos indígenas e nos aspectos fundamentais de sua cultura (SCHADEN, 1974) ou ainda àquela que ficava presa a noção de assimilação, ou seja, acreditava que os índios seriam assimilados por culturas mais evoluídas e assim seriam descaracterizados enquanto tais (GALVÃO, 1957).

Essas armadilhas do poder foram, durante por muito tempo, aceitas pela Antropologia, por meio de modelos etnológicos, como os dualismos sociedades centrípetas/centrífugas ou modelos de identidade concêntricos/diametrais e também por outras disciplinas, como a História, que acreditou numa única história, linear e evolutiva; e a Arqueologia, que acreditou ser capaz de identificar e congelar no tempo técnicas cerâmicas especificas de determinados povos, por meios das Tradições.

Essas continuidades que se sustentaram e serviram de norte metodológico por anos, hoje frente aos dados empíricos e documentais já não são suficientes, por exemplo, para os Jê meridionais. Vários modelos propostos por essas disciplinas estão e continuam sendo questionados

\footnotetext{
${ }^{6} \mathrm{O}$ relato trata-se de uma urna funerária encontrada no município de Olimpia/SP. A urna é resultado de diferentes técnicas cerâmicas. Técnicas Jê e Tupi se mesclam. Provavelmente foi resultado de trocas, de diálogos, de aprendizados, o que evidência agencias e estratégias desses indígenas e do que essa urna representa enquanto tal. Para mais detalhes, sugiro ler minha dissertação.
} 
na medida em que trazem consigo ainda a ideia de uma cultura única, estática e sem movimento e agência.

Hoje, essas disciplinas e nós, enquanto antropólogas e antropólogos estamos sendo chamados constantemente a uma abertura epistêmica, contribuindo assim para o desmoronamento de uma episteme altamente monolítica, ou seja, fechada tanto para outras formas de conhecimento como para o próprio Outro (CRUZ, 2016, p. 10/11).

A Antropologia, que tem um papel fundamental nesse despertar de outras perspectivas, outras relações, passa por um momento de reinvenção. Não por uma crise na posição de sujeitos de pesquisas, crises essa que já superou, como afirma Ribeiro (2005). Mas um momento de mudança e troca entre antropólogos de diferentes lugares no sistema mundial. Não podemos submeter a diversidade a um modelo que pretende ser único, mas temos que estabelecer novas condições de trocas acadêmicas e regimes de visibilidade.

Hofbauer (2009) talvez tenha razão, ao colocar o foco analítico de alguns estudos culturais girando em torno de três conceitos básicos: cultura, poder e identidade no processo de modernização e globalização. Articulada a uma crítica à história do Ocidente e ao colonialismo e suas grandes narrativas imbuídas de poder vista tanto na Antropologia, quanto na História e na Arqueologia, a busca é pela superação dos dualismos e oposição entre o Ocidente e o "resto do mundo”. Essa busca é uma tarefa árdua e que a curto prazo não parece mostrar soluções. Porém, aos poucos, travando diálogos e buscando trocar experiências multilocalizadas há de se sair dos binarismos criados por essas narrativas.

Dessa forma, seria possível uma revolução teórica nessas disciplinas e na produção de conhecimento como um todo, para que possamos assim, nos livrar desses discursos marcadas pelo poder e por interesses políticos rompendo com os mais diversos tipos de violência, em especial a epistêmica, que como produtores de conhecimento, nos cabe lutar e fazer a diferença. Uma diferença não só acadêmica, vista de forma romantizada e falada somente aos nossos pares, mas uma diferença que seja prática. Para que nós, em conjunto com nossas responsabilidades também políticas, possamos fazer surtir efeitos práticos no cotidiano de nossa disciplina e também de nossos sujeitos de pesquisas.

\section{REFERÊNCIAS DOCUMENTAIS}

\section{FONTES MANUSCRITAS}

CARTA dos oficiais da Câmara de Vila Boa, ao rei [D. José], expondo as atrocidades cometidas 
pelos índios Caiapós e insistindo na guerra ofensiva como único meio de repressão. 1757, Junho, 11. AHU_ACL_CU_008, Cx.14, D.856.

\section{REFERÊNCIAS BIBLIOGRÁFICAS}

ALMEIDA, Maria Regina Celestino de. John Manuel Monteiro (1956-2013): um legado inestimável para a Historiografia. Revista Brasileira de História. Vol.33, n.65, pp.399-403, 2013.

BARRETO, CRISTIANA. A Construção de um passado Pré-Colonial: Uma Breve História da Arqueologia no Brasil. Revista USP, São Paulo, n.44, p. 32-51, dezembro/fevereiro 1999-2000.

BENJAMIN, W. As Teses sobre o Conceito de História. In: Obras Escolhidas, Vol. 1, p. 222232. São Paulo, Brasiliense, 1985.

CASTAÑEDA, Q. E. The 'Ethnographic Turn' in Archaeology. Research Positioning and Reflexivity in Ethnographic Archaeologies. In: CASTAÑEDA, Q. E.; MATTHEWS, C. N. (Eds.). Ethnographic Archaeologies: reflections on stakeholders and archaeological practices. Plymouth: Altamira Press, p. 25-61, 2008.

CLASTRES, Pierre. Arqueologia da violência: pesquisas de antropologia política. São Paulo: Cosac Naify, 2004.

CRUZ, Felipe Sotto Maior. Indígenas antropólogos e o espetáculo da alteridade. Série Antropologia, vol.456, DAN/UNB, 2016.

DIAS, Adriana Schmidt. Novas perguntas para um velho problema: escolhas tecnológicas como índices para o estudo de fronteiras e identidades sociais no registro arqueológico. Boletim do Museu. Paraense. Emílio Goeldi. Ciências Humanas, Belém, v. 2, n. 1, p. 59-76, jan.-abr. 2007.

ETCHEVARNE, Carlos. O sítio de tradição Aratu de Água Vermelha, Reserva Indígena Caramuru Paraguaçu, e suas implicações arqueológicas e etno-políticas. Cadernos de Arte $\boldsymbol{e}$ Antropologia, Vol. 1, No 1 | -1, 53-57, 2012.

FAUSTO, Carlos. Inimigos fiéis: história, guerra e xamanismo na Amazônia. São Paulo: EDUSP, 2001.

FERNANDES, Florestan. A função social da guerra na sociedade tupinambá. São Paulo: EDUSP, 2a. Edição, 1970.

FUNARI, Pedro Paulo A. Archaeology in Brazil: politics and scholarship at a crossroads. World Archaeological Bulletin, Southampton, v.5, p.123-132, 1991.

FUNARI, Pedro Paulo A. O amadurecimento de uma Arqueologia Histórica Mundial. Revista de História, São Paulo, n. 135, p. 163-168, dez. 1996.

FUNARI, P.P.A. A Arqueologia Histórica em uma perspectiva mundial. In Arqueologia da Sociedade Moderna na América do Sul, Cultura Material, Discursos e Práticas. Andrés Zarankin e María Ximena Senatores (orgs), Buenos Aires, Ediciones del Tridente, 107- 116, 2002.

FUNARI, Pedro Paulo A. Arqueologia no Brasil e no mundo: origens, problemáticas e tendências. Ciência e Cultura. Vol.65, n.2, pp.23-25. ISSN, 2013. 
GALVÃO, Eduardo. Estudos sobre aculturação dos povos indígenas no Brasil. Revista de Antropologia. v.5, n. 1, 1957.

GASPAR, M. D. História da Construção da Arqueologia Histórica Brasileira. Revista do Museu de Arqueologia e Etnologia, 13:269-301, 2003.

GHENO, Diego Antônio; MACHADO, Neli Teresinha Galarce. Arqueologia Histórica Abordagens. História: Questões \& Debates, Curitiba, n. 58, p. 161-183, Editora UFPR. 2013.

HOFBAUER, Andreas. Entre olhares antropológicos, e perspectivas dos estudos culturais e póscoloniais: consensos e dissensos no trato da diferença. In: Antropolítica, no. 27, $2^{\circ}$ sem, 2009.

INGOLD, T. Trazendo as coisas de volta à vida: emaranhados criativos num mundo de materiais. Horizontes antropológicos. Vol.18, n.37, pp.25-44, 2012.

LÉVI-STRAUSS, Claude. Guerra e comércio entre os índios da América do sul. In: SCHADEN, Egon (org) Leituras de etnologia brasileira. São Paulo: Nacional, 1976. p. 325-339

MARTINI, Daniel Moretto. Na Trilha dos Bororo: Um Histórico das Relações com os Paulistas. Anais do I Encontro de Pesquisa de Graduação em História. Campinas: Unicamp, 2008.

MARTIUS, Karl Friedrich Philipp von. O Estado de direito entre os autóctones do Brasil. Revista do Instituto Histórico e Geográfico de São Paulo, São Paulo, v.11, p.20-82, 1907.

MONTEIRO, J. M. Tupis, Tapuias e Historiadores. Estudos de História Indígena e do Indigenismo. Tese (Livre Docência). Campinas: Unicamp, 2001.

NEVES, E. Twenty Years of Amazonian Archaeology in Brazil. Antiquity 72(277): 625-32, 1998.

NOELLI, Francisco Silva; FERREIRA, Lúcio Menezes. A persistência da teoria da degeneração indígena e do colonialismo nos fundamentos da arqueologia brasileira. História, Ciências, Saúde - Manguinhos, Rio de Janeiro, vol.14, n.4, pp.1239-1264, 2007.

QUIJANO, Aníbal. Colonialidad del poder, cultura y conocimiento en América Latina. In: Dispositio, vol. 24, no.51, 1999.

QUIJANO, Aníbal. Colonialidade do poder, eurocentrismo e América Latina. In: LANDER, Edgardo (org). A colonialidade do saber: eurocentrismo e ciências sociais. Perspectivas latinoamericanas. Buenos Aires, Colección Sur Sur, pp.118-142, 2005.

RIBEIRO, Gustavo Lins. Antropologias mundiais: cosmopolítica, poder e teoria em antropologia. In: Série Antropológicas, v.379, 2005.

SCHADEN, Egon. Aspectos fundamentais da cultura guarani. São Paulo: EPU/Edusp, $3^{a}$ edição, 1974.

SILVA, Fabíola A. Mito e arqueologia: a interpretação dos Asurini do Xingu sobre os vestígios arqueológicos encontrados no parque indígena Kuatinemu - Pará. Horizontes Antropológicos, 8 (18): 175-187, 2002.

SILVEIRA, F. L. A. da; LIMA FILHO, M. F. Por uma antropologia do objeto documental: entre a alma nas coisas e a coisificação do objeto. Horizontes antropológicos, Porto Alegre, v. 11, n. 23, 2005. 
DOCUMENTOS HISTÓRICOS E ARQUEOLÓGICOS COMO LOCUS DE INVESTIGAÇÃO, PODER E REPRESENTAÇÃO

Gabriela Gonçalves Junqueira

TURNER, Terence. Os Mebengokre Kayapó: história e mudança social, de comunidades autônomas para a coexistência interétnica. In: CARNEIRO DA CUNHA, M. (org). História dos índios no Brasil, São Paulo: Cia das Letras, p. 311 - 338, 1992. 